\title{
Posterior Pole of the Lens
}

National Cancer Institute

\section{Source}

National Cancer Institute. Posterior Pole of the Lens. NCI Thesaurus. Code C33375.

The center of the dorsal portion of the ocular lens. 